\title{
Chediak-Higashi Syndrome in Accelerated Phase
}

\author{
Nidhya Ganesan ${ }^{1,2} \cdot$ Prasanna N. Kumar ${ }^{1}$
}

Received: 21 January 2017/Accepted: 22 March 2017/Published online: 27 March 2017

(C) Indian Society of Haematology \& Transfusion Medicine 2017

A two-month-old boy, born to consanguineous parents, presented with high grade fever for 5 days. On examination he was febrile, pale with generalized hypo pigmentation of skin and hair, hepatosplenomegaly and cervical lymphadenopathy. He had a past history of recurrent respiratory tract infections. Splenomegaly of $2.5 \mathrm{~cm}$ was noted at birth. Complete blood count-total count $3.1 \times 10^{3} / \mu \mathrm{l}$, haemoglobin $7.4 \mathrm{~g} / \mathrm{dl}$, and platelet count $24 \times 10^{3} / \mu \mathrm{l}$. Primary blood and urine cultures were sterile. Peripheral smear showed pancytopenia with large eosinophilic inclusions in the lymphocytes (Fig. 1). Bone marrow revealed large coarse azurophilic granules in the cytoplasm of many of the myeloid precursors and mature granulocytes including eosinophils (Figs. 2, 3).

Erythrophagocytosis was evident in the marrow histiocytes (Fig. 4). Serum iron was $28 \mu \mathrm{g} / \mathrm{dl}$, ferritin $>2000 \mathrm{ng} / \mathrm{ml}$ and triglycerides were $325 \mathrm{mg} / \mathrm{dl}$. With the presence of six of the eight diagnostic criteria for HLH being present i.e. fever, splenomegaly, pancytopenia, hypertriglyceridemia, hyperferritenemia and haemophagocytosis in the bone marrow, a diagnosis of Chediak-Higashi syndrome with haemophagocytic lymphohistiocytosis (accelerated phase) was made. The child was treated with IV ceftriaxone and vancomycin. However his condition deteriorated and he expired.

Chediak-Higashi syndrome (CHS) is a rare, autosomal recessive disorder that affects multiple systems of the body mainly the immune system [1]. The clinical manifestations of

Nidhya Ganesan

nidhyaganesan@yahoo.com

1 Department of Pathology, PSG Institute of Medical Sciences and Research, Peelamedu, Coimbatore 641004, India

2 New No 30, VMC Colony, Robertson Road, RS Puram, Coimbatore, India

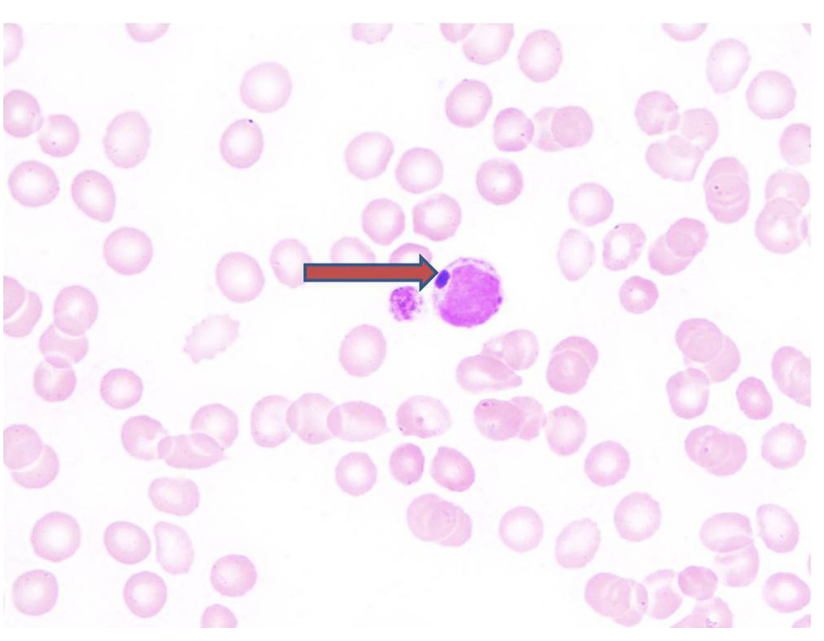

Fig. 1 Lymphocyte inclusion (indicated with red arrow)

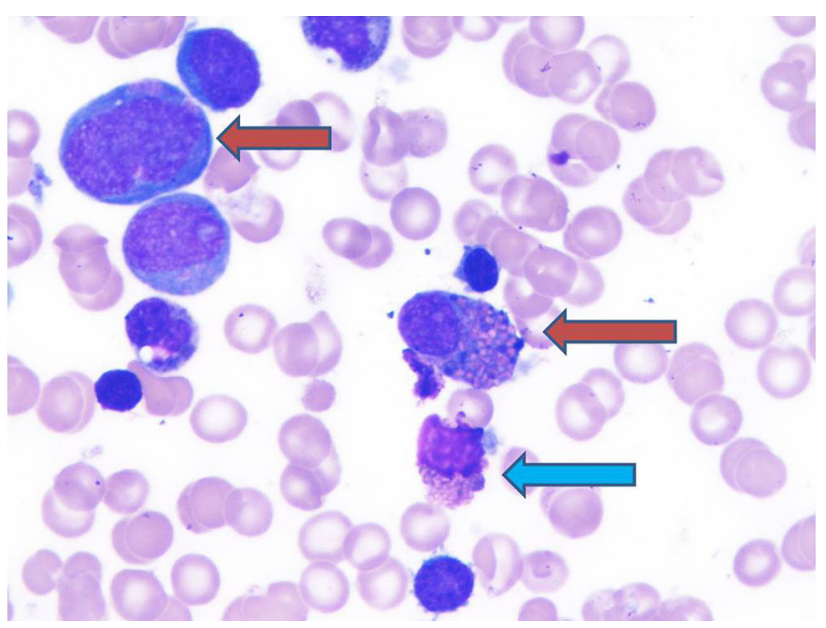

Fig. 2 Large coarse granules are present in the cytoplasm of the myeloid precursor (indicated with red arrow) and eosinophils (indicated with blue arrow) 


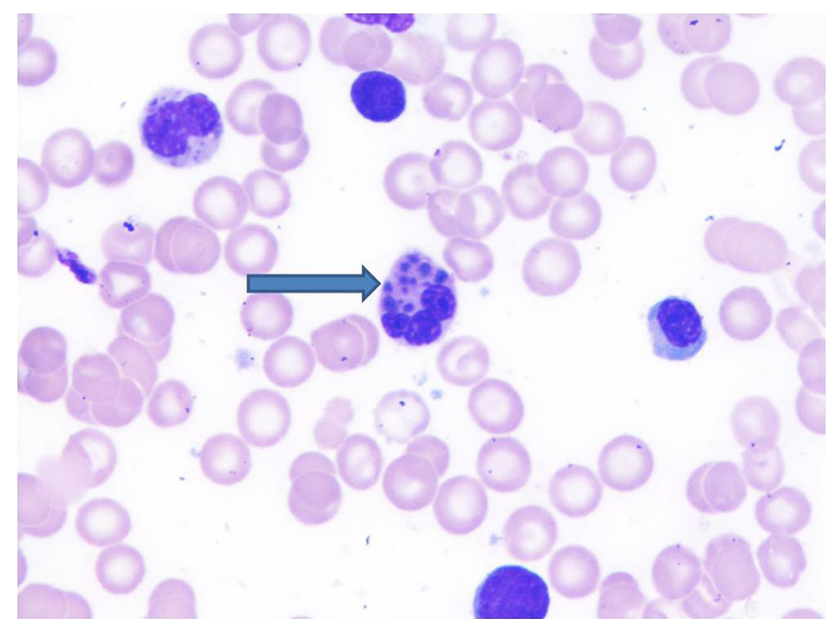

Fig. 3 Giant granules in the cytoplasm of neutrophils (indicated with blue arrow)

CHS in accelerated phase include high fever, neurological abnormalities, lymphadenopathy, hepatosplenomegaly, pancytopenia, abnormal giant granules in peripheral blood and bone marrow, lymphohistiocytic infiltration in liver, spleen and lymphnodes [2].The only treatment is allogenic haematopoietic stem cell transplantation (HSCT). The prognosis is poor [3].

\section{Compliance with ethical standards}

Conflict of interest Authors declared that they have no conflicts of interest.

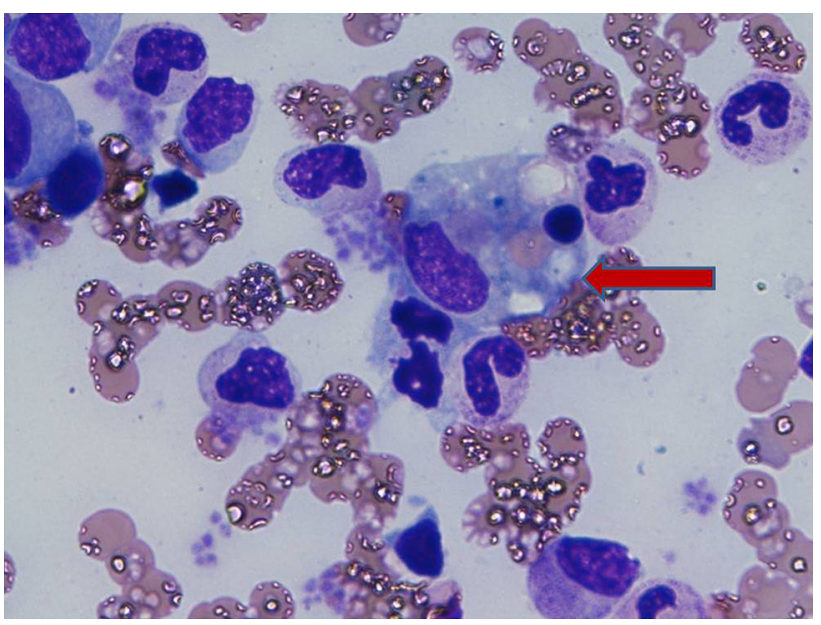

Fig. 4 Erythrophagocytosis (indicated with red arrow)

\section{References}

1. Ward DM, Shiflett SL, Kaplan J (2002) Chediak-Higashi syndrome: a clinical and molecular view of a rare lysosomal storage disorder. Curr Mol Med 2(5):469-477

2. Bouatay A, Hizem S, Tej A, Moatamri W, Boughamoura L, Kortas M (2014) Chediak-Higashi syndrome presenting in accelerated phase: a case report and literature review of the literature. Indian J Hematol Blood Transfus 30(1):223-226

3. Kaplan J, De Domenico I, Ward DM (2008) Chediak-Higashi Syndrome. Curr Opin Hematol 15(1):22-29 